\title{
El Municipio y la ciudad de Segovia
}

\author{
Sobre el origen de Segovia
}

La fundación de Segovia se desconoce.

Dejando a un lado las fantásticas aseveraciones acerca de la fundación de esta ciudad que Diego de Colmenares inserta en su historia de Segovia, las cuales no pueden tomarse más en serio que otras muchas de que están plagados los falsos cronicones, es lo cierto que Segovia aparece ya citada en el siglo II antes de Jesucristo. Plinio la incluye entre las seis ciudades de los arévacos y Tito Livio habla de ella al hacer la historia de las guerras contra Sertorio. Que su origen es aún más lejano, lo prueban el hecho mismo de su nombre, de indiscutible raíz ibérica, que perdura sin mudanza a través de los siglos, y esas figuras graníticas de jabalíes, vulgarmente conocidas por "las marranas" que pregonan elocuentemente su filiación celtíbera. Recientes excavaciones en lugares próximos a Segovia han permitido hallar restos de cerámica y otros utensilios neolíticos que atestiguan la existencia de una población en las inmediaciones. En el itinerario de Caracalla, Segovia aparecía como la mansión 18 en la ruta de Emérita a César Augusta. Con todo, no puede darse fecha exacta de su fundación, pues se desconocen más remotas noticias.

El Municipio de Segovia tiene una extensión superficial de 19 kilómetros cuadrados, y no ha sufrido variación alguna desde la antigüedad por agregación ni segregación. En ocasio- 
nes se insinuó la conveniencia de anexionarle el Municipio de San Ildefonso (La Granja), pero nunca llegó a plantearse en serio el problema.

Se halla situado a $\mathbf{1 . 0 0 0}$ metros corridos sobre el nivel del mar, en la meseta castellana a los pies de la vertiente Norte del Guadarrama, y con la célebre montaña llamada "La mujer muerta" al frente. Su clima, muy frío en invierno y templado en verano, goza justa fama de sano por la atmósfera limpia y despejada que se disfruta en todo tiempo.

En su tierra, no muy fértil, sino más bien pobre, se da la explotación agrícola de tipo medio-de 5 a 20 hectáreas-desconociéndose el latifundio, lo mismo en este Municipio que en toda la provincia, y no presentándose, por tanto, los problemas inherentes a los mismos. El problema agrario y sus secuelas de orden social y político es ajeno a esta tierra. Se cultivan primordialmente los cereales trigo, centeno, cebada y algunas leguminosas de grano seco. Pero como en todos los Municipios en que el carácter urbano predomina sobre el agrario, el aspecto agrícola es subalterno y no determina la fisonomía material ni moral de la ciudad.

Le bañan los ríos Eresma y Clamores, y prácticamente no existe explotación forestal, pues si bien el Municipio posee extensos pinares, se hallan en otros términos municipales, y aun fuera de la propia provincia de Segovia. En cambio, posee una riqueza ganadera, singularmente de la especie lanar, de relativa importancia, y la vacuna, auque no demasiado importante en cantidad, en calidad es excepcional, estando considerada la carne de vacuno de esta provincia como la mejor de España en punto a paladar, siendo esto debido a los magníficos pastos de esta vertiente de la sierra.

Sobre este territorio, someramente descrito en sus caracteristicas externas, se alza Segovia, la vieja Segovia de rancia fisonomía castellana, seca, austera, cargada de siglos de tradición, de cultura, de arte, de costumbrismo; pobre si se quiere, pero con un abolengo de nobleza insuperable e insuperado y albergando en su alma todas las virtudes quintaesenciadas de Castilla, madre de pueblos y de razas. 


\section{VICISITUDES IMPORTANTES DE SU HISTORIA}

Es indudable que, dada su posición estratégica en el centro de la peninsula, situada en las rutas guerreras y comerciales de los viejos tiempos, Segovia hubo de pasar por las vicisitudes comunes a otros pueblos del interior.

Sin embargo, no queda constancia de que fuese visitada o poseída de fenicios y cartagineses. En el siglo II antes de Jesucristo, Segovia aparece ya en poder de Roma, si bien combatiente contra ella en cuantas ocasiones se presenta coyuntura. De la excepcional importancia que al correr del tiempo la ciudad llega a tener para los romanos, son buena prueba la erección del grandioso acueducto, la obra de captación de aguas en la sierra y su conducción y la crecida serie de lápidas funerales que existían en diversos lugares, algunas con inscripciones de nombres correspondientes a encumbradas familias romanas. Aún pueden verse varias de ellas sirviendo de base en diversos puntos del recinto murado.

Tomada la península.por los pueblos de la Europa Central, nada se conoce de cierto respecto a los avatares sufridos por Segovia bajo' las distintas invasiones, aunque se afirma por algún historiador que fué asolada por los vándalos; asimismo sucede bajo el imperio visigodo, si bien la constancia de ciertos hechos significativos como, por ejemplo, el existir algunos Obispos en Segovia durante los siglos vi y vir hacen suponer que la vida era pacífica y no se acarrearon grandes cambios.

Nada puede afirmarse de cierto acerca de lo acontecido en los siglos de dominación musulmana, ya que las noticias de dichas épocas son nulas o muy contradictorias. Parece probable que los invasores del Sur la ocupasen sin asedio ni conquista, continuando en su incruenta posesión hasta ser arrojados de su recinto. Dicen algunos cronistas que la ciudad fué reconquistada por el Conde Fernán González, en el siglo x, aunque, dando por cierto este suceso, debió de ser nuevamente perdida y recuperada diversas veces, coyunturas a que la exponía su situación fronteriza. En 1071, Ali-Maimón o Almamún, Alcaide de Toledo, cayó sobre Segovia arrasándola por completo y cortan- 
do 36 arcos del acueducto, en el trozo de la arquería sencilla, los cuales permanecieron derruídos hasta 1484 que, por mandato de los Reyes Católicos, los rehizo Fray Juan de Escobedo, monje del Parral.

En 1079 fué definitivamente reconquistada la ciudad por Alfonso VI, y se comenzó su repoblación y la reedificación de iglesias y murallas. La vida de Segovia, a partir de esta fecha, es la de un pueblo que se afana por organizarse y fundamentar su vida sobre bases sólidas. Los Reyes de Castilla la hacen objeto de grandes donaciones, como reconocimiento a los buenos servicios de los segovianos, y el territorio de su jurisdicción crece prodigiosamente. No obstante, aún ha de experimentar Segovia muchos sinsabores, unas veces por rivalidades de la nobleza inquieta y otras por intrigas reales o palatinas. En 1324, por ejemplo, el despótico gobierno de Doña Mencía del Aguila trajo como consecuencia motines y matanzas, siendo incendiada la iglesia de San Martín cuya torre se derrumbó. En 1464, el asalto a la ciudad de los partidarios de Don Alfonso, hermano de Enrique IV, fué ocasión de nuevos sangrientos disturbios y destrucciones. En 1520, el alzamiento comunero motivó cruentas luchas que terminaron con la existencia de la vieja catedral de Santa María, edificada en el siglo xir frente al Alcázar rea!. Pudieran añadirse a lo relatado otros muchos y sangrientos sucesos y asonadas de que fueron pródigos los siglos xIv y xv. En 1598 y 99 , una tremenda peste, de virulencia brutal, causaba 12.000 muertos y la ruina y desolación de la Segovia floreciente de los días áureos.

\section{SUCESOS DE RELIEVE NACIONAL}

La historia de Segovia ofrece abundante copia de acontecimientos cuya influencia unas veces traspasa los ámbitos locales, con la consiguiente resonancia en la vida nacional, y otras se reducen a hechos de importancia menor, que interesan exclusivamente en el desarrollo de la existencia ciudadana. De los primeros pueden citarse, como de más relieve, los siguientes: La erección del acueducto; la restauración de la acuñación de mo- 
neda desde los mismos días azarosos aún de Alfonso VI; la decisiva participación segoviana en las conquistas de Madrid, Cuenca y Córdoba ; la reunión de Cortes en el Alcázar, por los monarcas castellanos, de algunas de las cuales surgen acuerdos de importancia extrema como, por ejemplo, la mudanza en el cómputo del tiempo decretada en las Cortes reunidas por Juan I en 1383; el asalto y toma de Segovia por los partidarios de Don Alfonso, hermano de Enrique IV, en 1467 ; ra proclamación de Isabel I de Castilla, en el atrio de la antigua iglesia de San Miguel, el 13 de diciembre de 1474; el levantamiento comunero en 1520, acaudillado en Segovia por Juan Bravo; las bodas de Felipe II con Ana de Austria en el Alcázar, el 14 de noviembre de 1570 ; la instalación del Real Colegio de Artillería en el referido Alcázar segoviano a finales del siglo xvirr; la ocupación francesa de la ciudad y el asalto de la facción Zariátegui, el 4 de agosto de 1837.

\section{HECHOS Históricos DE CARÁCTER LOCAL MÁS SALIENTES}

Siendo la historia de una ciudad sucesivo encadenamiento de hechos de todo relieve, es indudable que, desde el punto de vista local, todos los acontecimientos adquieren interés, aun los más nimios, pues en la esfera de su importancia contribuyeron de algún modo al desarrollo histórico. Pero como este supuesto obligaría a relatar todos y cada uno de los sucesos que tejen el hilo de la historia segoviana, haremos mención únicamente de aquellos cuyo volumen se presenta como más destacado dentro del ámbito local: Reconquista definitiva de Segovia, en 1079; edificación de la antigua catedral de Santa María, en el siglo xII ; venida de Santo Domingo de Guzmán, a principios del xIrr, y fundación del Convento de la Orden Dominicana; milagro de "María del Salto", en 1237; motines provocados por el despótico gobierno de Doña Mencía del Aguila, en 1324; milagro del Corpus Christi, en 1410 ; venida y predicación de San Vicente Ferrer, en 1411 ; fundación del Monasterio del Parral, en 1447 ; fundación de la Casa de la Moneda por Enrique IV, en 1454 ; 
restauración del Acueducto, en 1484; edificación del Convento de Santa Cruz, en el mismo año y siguientes; expulsión de los judíos, en 1492; destrucción de la Catedral de Santa María, en 1520 ; colocación de la primera piedra de la actual, en 1525 ; hundimiento de la antigua Iglesia de San Miguel, en 1532 ; traslado de las reliquias a la nueva Catedral, en 1558, y llegada a Segovia, con este motivo, de Lope de Rueda, para representar sus obras; apogeo de la industria segoviana de los paños; venida de Santa Teresa de Jesús, en 1574, y fundación del Convento de Carmelitas Descalzas; fundación por San Juan de la Cruz del de Carmelitas Descalzos, en 1587; inauguración del Santuario de la Fuencisla, en 1610; destrucción de la aguja gótica que remataba la torre de la Catedral, por un rayo, en 1614; publicación de la historia de Segovia de Colmenares, en 1637 ; fundación de la Escuela de Dibujo, en 1778; creación de la Sociedad Económica de Amigos del País, en 1780, e inauguración del ferrocarril.

\section{VIDA ECONÓMICA ANTIGUA}

No está suficientemente estudiado el desarrollo económico de Segovia en los pasados siglos y aún puede afirmarse que fal$\tan$ noticias relativas a algunos, sobre todo de aquellos que siguen a la reconquista de la ciudad. Puede conjeturarse, por alusiones esparcidas acá y allá, que en los siglos subsiguientes a la toma de Segovia por Alfonso VI, la ciudad pasa por una dilatada era de reconstrucción y organización; las industrias incipientes se van desarrollando poco a poco y la vida económica, por tanto, sigue una actividad reducida a las más generales cuestiones, paralela al proceso todo de la vida ciudadana. El Ayuntamiento encauza y guía sus actuaciones hacia la solución de los problemas cotidianos de la existencia del común, mientras se pone en situación de ir obteniendo producto de los extensos predios que la magnanimidad y cariño hacia Segovia de los Reyes castellanos van granjeándola. Son la Iglesia, los Nobles Linajes y familias poderosas quienes contribuyen a sostener una primaria actividad industrial, basada en restauración de 
templos y ornamentos religiosos, necesidades de guerra, etcétera, mientras la existencia ciudadana, fuera de estos aspectos, pasa por un tranquilo proceso netamente artesano. Se sabe que ya en el siglo xiII habían ganado fama los paños segovianos. La riqueza ganadera de la tierra de Segovia-célebre desde la época de dominación romana-, era fundamento natural de algunas industrias, derivadas de aquélla, que andando el tiempo ejercerían capital influencia en la economía de la ciudad. Con los paños, iniciaban su marcha ascendente los curtidos y la sombrerería.

Los siglos xIv y xv se caracterizan por la agrupación de los operarios y menestrales en cofradias que, si bien tienen al principio un fin puramente religioso y espiritual, con aspecto bené. fico en determinados casos, desembocan en la constitución de los gremios, poderosas organizaciones que alcanzan su más alto exponente en el siglo xvi, en las cuales se tiende ya a la regla. mentación rigurosa del trabajo y de sus materias básicas. Estos gremios que llegan a ser francamente opulentos en algunas manifestaciones industriales, influyen decididamente en la vida social y económica de Segovia.

* Por su parte, el Municipio ha ido organizando su existencia y los medios de que puede disponer para cubrir las múltiples necesidades de la vida ciudadana. Sin embargo, aun cuando es muy extenso el patrimonio que posee (en común con la Universidad de la tierra, o tierra de Segovia, y los Nobles Linajes), no bastan sus productos para atender holgadamente al cúmulo de obligaciones que sobre el Municipio pesan. Pruébase esto por el hecho muy reiterado a lo largo de la existencia segoviana: de que el Concejo se ve constantemente en la necesidad de imponer sisas y gravámenes sobre los artículos de consumo y tomar dinero a censo cuantas veces ha de atender al pago de obligaciones imprevistas. Hay algunos momentos, bien con ocasión de visitas regias, pestes $u$ otros motivos determinantes de extraordi. narios desembolsos, en que el Municipio segoviano adquiere deudas que sobrepasan los $\mathbf{1 0 0 . 0 0 0}$ ducados. Es decir, que si bien la poderosa industria de los paños y las otras no tan florecientes pero dignas de estimación por su provecho, atraen riqueza a la 
ciudad, la existencia económica del Ayuntamiento segoviano no participa de la misma holgura.

Sus arcas se nutren a base de diversos gravámenes sobre las especies de consumo, arriendo de las carnicerías, idem de los pesos de la harina, de las pescaderías, de las tabernas del vino caro, derechos sobre elaboración de la moneda, arriendo de los pesos del aceite, producto de los pastos, arriendos de las fincas, derechos sobre lanas, ídem de matadero, mercedes de agua de la cacera y del Clamores a establecimientos de tintorería, tenerías, etc. y a diversos particulares, multas impuestas por los Regidores, fieles y procuradores del Común, participación en las que imponían los veedores de los gremios, derechos de examen de maestros y oficiales de los oficios y otros análogos ingresos.

En cambio, había de subvenir al arreglo y limpieza de calles, reparación de puentes y caminos, obras de ornato de la ciudad, reparación de caños y fuentes públicas, salarios de Regidores, escribanos, médicos de pobres, cirujanos, personal diverso de guardas, alguaciles, trompetas, ministriles, pregoneros, etcétera; subvenciones para fiestas diversas, limosnas a comunidades y obras de la Catedral, sostenimiento de la cárcel, alhóndiga y demás establecimientos de carácter municipal, pago de los crecidos subsidios reales y cuotas señaladas por la Corona, tales como contribución de millones, etc.

En cuanto al nivel de la vida en las pasadas edades puede tomarse como muestra el hecho de que durante el siglo xvi, por ejemplo, el jornal medio de un obrero corriente oscila de dos a tres reales de vellón diarios. Y paralelamente, el precio de la fanega de trigo, que constituye el regulador del nivel de vida, variaba de los cuatro a los seis reales. Como quiera que con arreglo a dicho módulo se valoraban todas las demás cosas, despréndese que la existencia por entonces gozaba de un equilibrio armónico, exento de dureza y dificultades.

En los siglos xvir, xvin y xix, consecuentemente a la despoblación y empobrecimiento de la ciudad, fué haciéndose cada vez más angustiosa la situación económica del Municipio segoviano, hasta alcanzar momentos de honda crisis. 


\section{VIDA ARTÍSTICA}

En los siglos que suceden a la reconquista de la ciudad, la vida artística de Segovia se contrae en absoluto a la restauración de las iglesias derruídas-algunas de las cuales acusan aún su origen mozárabe anterior a aquel acontecimiento-, dejando vigorosas muestras de un arte tan característico como pleno de gracia ingenua en ese tesoro de capiteles, ménsulas, canecillos, ábsides, etc., que la espléndida floración del románico va creando por todo el recinto de la Segovia murada y aun de los barrios externos y perdura hoy para gloria cumplida de la ciudad. Y con esta arquitectura de sólidas líneas, de macizos contornos, se cultiva también una pintura pareja en estilo de la que sobreriven escasos restos: atrio de San Martín e interiores de San Nicolás y la Trinidad, aunque pudiera ser que, bajo la capa de yeso que recubre el interior de casi todas las iglesias románicas de Segovia, existan otras muestras de aquel arte. Desde luego, ni un solo nombre nos ha legado la historia de la ciudad por el cual venir en conocimiento de los artistas que crearan tanta riqueza.

Es ya en el siglo xv cuando, con ocasión de las obras de edificación del Monasterio del Parral, Convento de Santa Cruz y Sala del Trono del Alcázar, nos quedan algunos nombres de maestros, alarifes, escultores, entalladores y pintores que en aquéllas intervienen. En el primero, trabajan los hermanos Guas, que tanta influencia han de ejercer en la arquitectura segoviana; Salvador Almonacid, Bartolomé Fernández, Pedro Polido, Francisco Sánchez, Juan de Ruesga, Juan Rodríguez, Blas Hernández, Jerónimo Pellicer, Francisco González, Luis Giralde y Juan Campero, segovianos unos y otros venidos de distintos lugares. En Santa Cruz, trabajan Juan de Herrera y Diego de Urbina, pudiéndose asegurar que también intervendrian los hermanos Guas. La Sala del Trono del Alcázar, mandada erigir por Enrique IV, es una muestra primorosa del delicadísimo arte del alarife morisco Xadel Alcalde.

La erección de la actual Catedral, da motivo para que un. plantel de arquitectos y artífices de todo linaje dejen en ella 
las más exuberantes muestras de sus estilos. Citaremos a los arquitectos Juan Gil de Hontañón y su hijo Rodrigo Gil de Hontañón; Juan de Mugaguren y Pedro de Brizuela. Los entalladores Mateo y Juan Inverto, el excelente pintor segoviano Alonso de Herrera ; los maestros de cantería Pedro Monasterio, Nicolás González y Juan Campero, por no hacer más extensa la relación. En la segunda mitad del siglo xvi, trabaja en Segovia Jerónimo de Amberes, al cual se deben los sepulcros que existen en la llamada Capilla de los Viejos.

Otro arte se cultiva en la ciudad, en los siglos xv, xvi y xvir, con singular maestría y acierto: la platería. Por las iglesias de Segovia y aun por muchas de la provincia, quedan ejemplos magníficos de la perfección y excelencia de las obras de los plateros segovianos en custodias, relicarios, cruces parroquiales, etc. Pueden citarse, como más renombrados, Antonio de Oquendo, Antonio Muñoz, Diego Muñoz, Antonio de Olmedo, Juan de Olmedo y Juan Pérez. En Segovia trabajó también el gran Arfe, que durante algún tiempo estuvo destinado como ensayador en la casa de la Moneda.

Otras muchas manifestaciones artísticas podrían añadirse a lo relacionado, juntamente con los nombres de sus numerosos cultivadores, que omitimos por no hacer en extremo dilatada esta exposición. Con lo anotado es suficiente para dar una idea de que Segovia mantuvo vivas las actividades del arte en todas las épocas.

Monumentos más notables. Datos relativos a su estilo, époCA, CONSTRUCTOR, OBJETO Y SINGULARIDADES DE LOS MISMOS

El Acueducto.-Tanto por su antigüedad como por la grandiosa arrogancia de su fábrica, corresponde la primacía en el orden monumental de Segovia al soberano Acueducto, blasón y rúbrica de la ciudad milenaria. Le forman 169 arcos, parte en línea sencilla y el resto en arquería doble, alcanzando una altura de $\mathbf{3 0}$ metros sobre el famoso Azoguejo, que loara Cervantes. Su trazado se desarrolla en una longitud de 800 metros 
y sobre su lomo augusto siguen cantando las aguas como en los remotos días de su erección.

Dase como cierta su filiación romana, aunque diversos autores sostienen otras teorias respecto a su origen, y parece datar del siglo I de nuestra era, tal vez entre los reinados de Vespasiano y Trajano. Probablemente su construcción fué obra de carácter comunal y desconócese en absoluto fecha y autor de $\tan$ magno proyecto. Sobre la cartela que da frente al Azoguejo, hasta bien entrado el siglo xvi, existieron restos de las letras de bronce que, indudablemente, consignaban los detalles relacionados con su construcción. En su célebre "Diálogo de la lengua" dice Juan de Valdés que aún existían algunas de aquéllas por la época de la publicación de su obra.

En 1071, Almamún cortó 36 de sus arcos que, en 1484, reconstruyó Fray Juan de Escobedo. A principios del siglo xIx fueron derribadas las ocho casas que perduraban recostadas en los arcos, en el Azoguejo, prestando un sello de abigarrado maremagnun al castizo paraje y restando visualidad y esbeltez al Puente grandioso que perpetúa su traza solemne y magnífica a través de los siglos como gigante solitario de remotos tiempos.

El Alcázar.-Aparece la primera noticia del Alcázar en los mismos turbulentos dias del reinado de Alfonso VI, poco después de la reconquista de la ciudad. Es muy posible que en ese agudo espolón roquero donde Segovia termina por poniente, se alzase con anterioridad algún baluarte o castro, ya que la situación del peñascal sobre las rutas del valle parecen indicar claramente su antigua misión vigía. Conjunto de edificaciones de distintas épocas, el Alcázar segoviano ha venido a ser como la más fiel representación del castillo del medievo, preciso de línea y audacia.

Por sus frías estancias, ampliándole y embelleciéndole, pasan diversos monarcas de Castilla: Alfonso VIII, Alfonso $\mathrm{X}$, Juan II, Enrique IV, Isabel I de Castilla y aun el mismo Felipe II realiza en él también algunas importantes obras. En sus grandes salas se va reuniendo cuanto de más fastuoso producen las artes ornamentales y suntuarias de cada época, hasta hacer del regio Alcázar fulgurante joya del tesoro artístico español. 
Todos los estilos, comenzando por el románico, dejan en el conglomerado de edificaciones que es esta magna residencia real la huella de su paso, aunque no son muy precisos los datos y noticias referentes a los artistas que en ella pusieron su genio. Sabemos de Xadel Alcalde, el exquisito alarife morisco; sabemos que en él trabajaron los hermanos Guas; más tarde, en los tiempos de Felipe II, los arquitectos Gaspar de Vega, Francisco de Mora y Pedro de Brizuela, dejan constancia de sus actividades.

En las estancias del Alcázar han nacido y han muerto príncipes; sus muros fortísimos conocieron asaltos y luchas sangrientas. Ha sido morada real, prisión, baluarte, escenario de fastuosos cortejos y de Cortes de Castilla. Tesoros de arte y riquezas tentadoras se guardaron en su recinto. A finales del siglo xviII, Carlos III le convierte en Real Colegio de Artillería, y, finalmente, un día de agosto de 1862, voraz incendio reduce a cenizas tanta maravilla artística como los siglos habian depositado en él. Veinte años más tarde, en 1882, se le restaura de nuevo, siguiendo en lo posible su anterior trazado y se le destina después a Archivo General Militar.

Pero Segovia es, sobre todo, el más rico museo de arte románico de España: vitrina magnífica donde se exhiben a. la admiración y al goce espiritual las viejas reliquias de los siglos remotos. En este conjunto de iglesias que van surgiendo al paso por las angostas e irregulares calles de la ciudad, encontramos espléndidos ejemplos de un arte que legó, a Segovia numerosas y solemnes realizaciones que hoy le hablan al espiritu un lenguaje apretado de emociones. Sin pretender en modo alguno agotar el tema y siguiendo un itinerario ordenado, vamos a mencionar estas viejas iglesias románicas que ofrecen al viajero el melado encanto de sus pretéritas formas:

San Andrès.-Iglesia de las postrimerías del siglo xII, con tres naves y dos ábsides; uno de ellos acaso el más hermoso ejemplar que posee la ciudad; la torre del templo es mudéjar, de ladrillo enlucido de cal; tiene esta iglesia un soberbio retablo, obra del siglo xvi, original de Mateo Inverto, con excelentes pinturas del segoviano Alonso de Herrera. 
San Esteban.-Aparece citado este templo entre los primeros del recinto murado, aunque su actual estado es consecuencia de obras muy posteriores. Posee también tres naves. Sin embargo, lo que hace de esta iglesia un extraordinario ejemplar es su torre, llamada "Reina de las torres bizantinas"; consta de cinco cuerpos que arrancan desde un basamento tan alto como la nave mayor. Derruído en 1894 su chapitel por un rayo y resentidos algunos de los cuerpos de esta torre magnífica, hubo de ser desmontada hasta su mitad rehaciéndose después, tras veinticinco años de lentísimas obras. Es monumento nacional. En una capilla de la iglesia consérvase un Cristo gótico, de brazo desprendido, procedente de la desaparecida iglesia de Santiago, que posee una leyenda similar a la del Cristo de la Vega, de Toledo. Admírase también en esta iglesia un esbelto atrio, en gran parte reconstruído últimamente.

San Quirce.-Pequeño templo que en su origen, al decir de algún cronista, fué abadía benedictina. Su aspecto denota una gran vejez, aunque su construcción no debe de remontarse a tiempos anteriores al xir. En esta iglesia fué sepultado Diego Enríquez del Castillo, cronista de Enrique IV, aunque no ha podido esclarecerse cuál fué el lugar exacto del enterramiento. Abandonada durante muchos años, fué pajera de la Intendencia militar, y, finalmente, en inminente estado de ruina, la adquirió la Universidad Popular Segoviana, salvándose así de su total destrucción. Es iglesia de una sola nave y tiene una torre rota de indudable antigüedad.

La Trinidad.-Es este, acaso, el templo románico que más controversia ha suscitado entre los historiadores y tratadistas de arte; el hecho de ostentar sobre una de sus portadas el lábaro santo hizo que por alguno de aquéllos se le asignase una antigüedad tan remota como de los tiempos de Recaredo. No obstante, más profundos y detenidos estudios han permitido establecer que su construcción data de los siglos xII y XIII, aunque en ella debieron de aprovecharse los restos de una iglesia mozárabe, fenómeno nada extraordinario en las iglesias de Segovia. Consta de una sola nave y la porción semicircular del ábside constituye un magnífico ejemplo de arquerías superpuestas, 
bellamente policromadas. Actualmente se llevan a cabo importantes obras para devolver a esta bellísima joya su pureza primitiva. En ella hay buenas pinturas, alguna debida al pincel de Ambrosius Benson. También posee una capilla con portada gótica, denominada de los Campo y Trinidad, donde están los enterramientos de estos fundadores que moraban en espléndida casona, frènte a la portada del mediodía. Un esbelto y característico atrio da realce a tan estupenda y deliciosa iglesia románica, que señorea ancha y maciza torre.

San Nicolás.-Sobre las cuestas de San Bartolomé se alza esta antigua iglesia, que ha sufrido muchos avatares; parece ser templo del siglo xII, y posee bella torre y ábsides armoniosos. Actualmente se están llevando a cabo en ella obras de consolidación y afianzamiento, ya que todo el edificio amenazaba ruina, constituyendo sus bellos ábsides un lamentable ejemplo de abandono y decadencia. Los trabajos que se realizan para su seguridad permitieron hace algunos meses descubrir importantes pinturas románicas y un sepulcro del siglo xirI, con la momia intacta de un caballero de aquellos remotos días. Cerrada al culto a fines del pasado siglo, vino a ser propiedad del Ayuntamiento y su recinto ha servido para los más extraños menesteres.

San Juan de los Caballeros.-Iglesia del siglo xIII, propiedad de los descendientes de don Daniel Zuloaga, que la adquirió a principios del actual siglo para instalar en ella vivienda y estudio de cerámica. Fué sede de los Nobles Linajes, institución aristocrática surgida a raíz de la reconquista, que tuvo gran influencia en la vida segoviana de los pasados siglos. En esta iglesia estaban los sepulcros de aquellos lejanos caballeros y el de Angelina de Grecia, mujer que fué de Diego González de Contreras. De ella fué párroco Diego de Colmenares, cronista e historiador de la ciudad, que permaneció sepultado en su recinto hasta la segunda mitad del siglo pasado en que se trasladaron sus restos al Monasterio del Parral. Posee el templo un hermoso atrio del románico más puro, con profusión de motivos ornamentales en capiteles y canecillos. Tiene también dos soberbias portadas, una ya de transición. La torre, hoy rota, fué se- 
gún antiguos cronistas tan alta como la de San Esteban. Sus ábsides son espléndidos de carácter y sabor.

San Sebastián.-Juntamente con San Juan de los Caballeros y la desaparecida de San Pablo, esta románica iglesia alcanzó vida fastuosa en pasadas centurias, como cumplía a un templo alzado en el corazón del barrio prócer. Es iglesia de una sola nave, con esbelta torre y ábside característico. Fué restaurada a principios del siglo actual por la V. O. T.; hoy es tempío de la Compañía de Jesús.

San Martín.-Como la Trinidad, también esta iglesia ha originado enconadas disputas técnicas; parece ser que gran parte de ella hállase edificada sobre los restos de otra iglesia mozárabe, dándose el caso poco corriente de que su torre gravita sobre el centro de la nave mayor.

La sucesiva adición de edificaciones ha originado un conjunto, en varios planos, no exento de gracia y armonía; tiene dos atrios, uno, del siglo xir que mira al Norte y estaba tapiado hasta hace pocos años; otro, del XIII, que se abre, esbelto y dorado, al mediodía. En él se distinguen residuos de pinturas románicas de la misma centuria. ¿La iglesia es de tres naves y posee buenas capillas, como la de los Herrera, donde duermen el sueño eterno antiguos caballeros de rancia estirpe: Herrera, del Río, Dávila, Bravo de Mendoza, etc.

Extramuros de la ciudad, en medio del laberíntico trenzado de los arrabales, existen otras interesantes iglesias románicas, dignas de aprecio por diversas circunstancias. Citaremos en primer lugar San Marcos, considerado como el más antiguo de los templos segovianos, sobrio y sencillo, como una iglesuca de un pueblecito perdido en la meseta y exactamente encuadrado en el ambiente del típico barrio que preside. Su aspecto abona la creencia en su lejano origen, aunque éste no se remonte a las fechas en cierto modo fabulosas que algún historiador le asigna.

La Veracruz.-Muy próxima a San Marcos, se alza la soberbia iglesia que en los albores del siglo xir edificaron los Caballeros Templarios. Fué, en un principio, un solo cuerpo, de forma poligonal, rodeando a otro interno donde existe el ara en que velaban sus armas los caballeros. Disueita la Orden del 
Temple, la originalísima y casi única iglesia pasó a depender de los Caballeros de San Juan, que la adosaron la torre que ahora ostenta. Poseía ricos ornamentos, cuadros y tallas que, al abandonarla sus poseedores en el siglo xvir, pasaron al inmediato pueblo de Zamarramala; entre sus piadosos tesoros contábase un trozo del leño de la Cruz, enviado a los Templarios por el Papa. La Veracruz es monumento nacional y ha sufrido críticos avatares en sus largos años de abandono e incuria.

San Lorenzo.-Al otro extremo del valle del Eresma, yérguese esta iglesia de San Lorenzo, que constituye uno de los más singulares y hermosos ejemplos del románico de Segovia. Fué edificada en el siglo xirr, alzándose en el pintoresco y característico arrabal de su nombre, de acusado sabor menestral; destacan en ella la torre mudéjar, de ladrillo, y unos hermosos ábsides de clásica hechura que riman perfectamente con la dorada teoría de su atrio admirable donde los labrados capiteles ponen su clara elegancia de formas.

San Justo.-He aquí un pequeño templo románico aureolado por las luces lejanas de la`leyenda: en él se guarda el célebre "Cristo de los Gascones" que la tradición legendaria hace venir a Segovia, en los comienzos del siglo. xiII, de modo extraordinario, a lomos de una mula. La iglesia tiene un ábside notable y la torre constituye un buen ejemplar clásico, aunque su último cuerpo aparece no poco desfigurado. La iglesia conserva algunas muestras de buena pintura. El célebre "Cristo de los Gascones", gótico en la traza, se encierra en una urna dorada de acusado barroquismo.

San Clemente.-Lo más notable en esta iglesia, de ancha y cuadrada torre maciza, es su ábside que se aparta un tanto del carácter de los otros ábsides de la ciudad, hasta el punto de constituir un ejemplo único, de indudable influencia francesa. Posee restos de un atrio, tapiado y encalado, y recientemente se acotó el paso a la plazoleta frontera de la iglesia, quedando también poco visible el ábside mencionado. Hoy, por efectos de antiguos rebajes en el desnivel de la calle, la puerta principal, también tapiada, ha quedado a bastante altura sobre el plano de 
aquéila. Es iglesia adscrita al inmediato convento de Religiosas Reparadoras.

Sañ Millán.-Una aureola de vejez extremada ciñe a esta hermosa iglesia, ya que por algunos cronistas se la supone edificada en el siglo $x$. Recientes y detenidos estudios parecen haber comprobado que es construcción de los siglos xII y xIII, asentada sobre el emplazamiento de otra anterior que también se denominó de San Millán. El hecho de que su torre sea desproporcionada evidentemente respecto al volumen de la iglesia y a que no parece edificada para ella sino para otra más reducida y anterior, confirma en cierto modo aquel supuesto. Tal como hoy es, resulta el más amplio de los templos románicos de la ciudad; consta de tres naves, cinco ábsides y dos atrios, poseyendo al interior bellos pilares rematados por capiteles únicos en la ciudad. Hace siglos estaba cubierta por una bóveda plana, del siglo XII, de factura morisca cuyas piezas se conservan en los desvanes del templo, muy semejante a la de la Mezquita de Córdoba. San Millán goza de una situación dominadora sobre el extenso barrio de su nombre, de antigua raigambre artesana y menestral.

Aún podríamos hacer mención de algún otro templo románico en su origen, como Santa Eulalia, el Salvador y Santo Tomás, en los que todavía se conservan restos del estilo inicial -un ábside, una torre, alguna arquería cegada-pero que ya revisten menos importancia dentro de la trascendencia del arte que anotamos, por sus deformaciones, añadidos y posteriores reformas. A todo lo mencionado, súmanse algunas portadas románicas del siglo xiII, como la del Palacio de los Contreras, o de las Casitas de las Canonjías, y restos de iglesias desaparecidas en su mayor parte, como San Pedro de los Picos, San Blas, etc.

\section{José M. Peláez Suárez}

Secretario del Excmo. Ayuntamiento de Segovia

(Continuará.) 